\title{
التفجيرات النووية الفرنسية في الجزائر كأحد أهم نماذج جرائم الإبادة الجماعية في القرن العشرين
}

\author{
شريفة كلاع \\ قسم الدراسات الدولية، كلية العلوم السياسية والعلاقات الدولية، جامعة الجزائر 3-الجزائر
}

(تاريخ القبول بالنشر:10 كانون الثاني، 2021)

الخلاصة

التيتم في هذا البحث التركيز على أهمية دراسة جرائم الإبادة الجماعية؛ وذلك من خلال تبيان أحد أهم النماذج تاريخية التي حصلت فيها

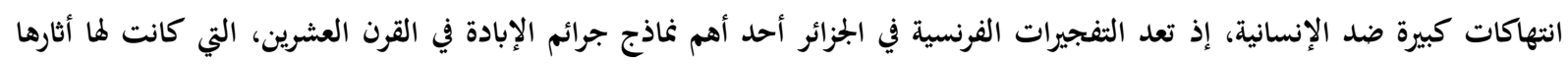

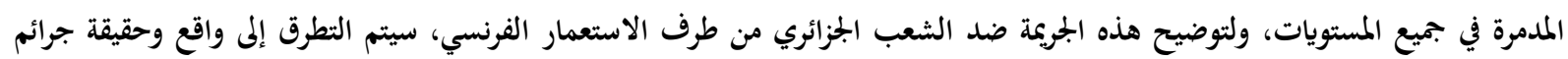

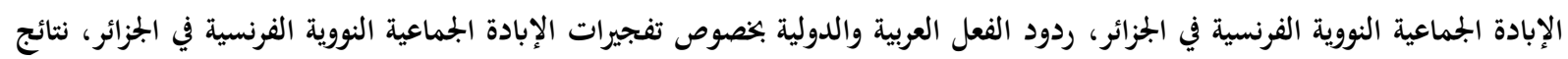

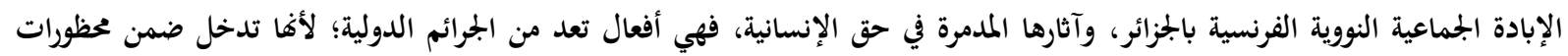

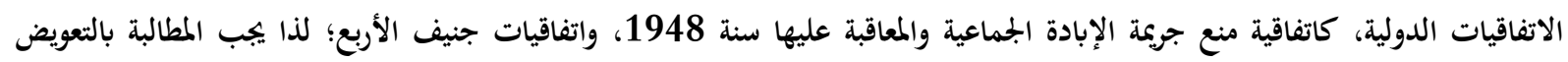
الفرنسي عن جرائم الإبادة الجماعية الناتجة عن التفجيرات النووية في الجزائر. الكلمات المفتاحية: جرائم - الإبادة الجماعية - الإنسانية - التفجيرات النووية الفرنسية - في الجزائر.

وأغمضت أعينهم بالقرب من التفجيرات كفئران بتحارب في

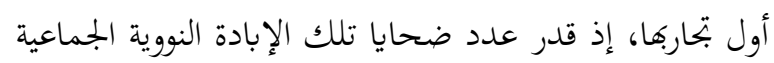
الفرنسية 42000 شهيدًا، كما خلّفت التفجيرات النووية

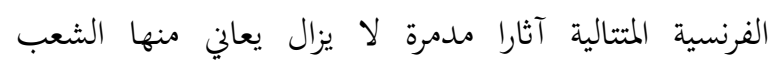
الجزائري إلى الآن، كتفشي أمراض السرطان، وتلوث آبار

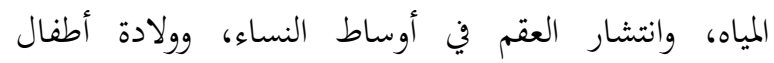

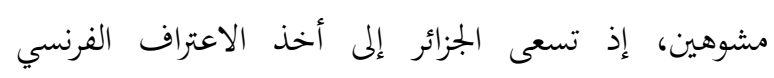
بجرائمها وطلب التعويضات لضحايا التفجيرات النووية. هدف البحث: يهدف البحث إلى تبيان إحدى جرائم الإبادة

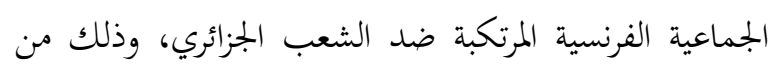
خلال التركيز على أهم تلك الجرائم الواقعة في القرن العشرين العربه

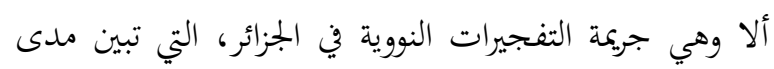

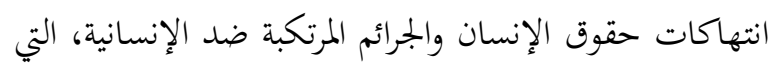

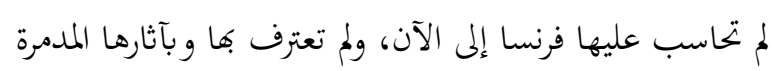
التي لا تزال تأثيراتحا قائمة يعاني منها الإنسان والطبيعة معًا.

\section{مقدمة}

شهدت الجزائر منذ احتلالها على يد المستعمر الفرنسي

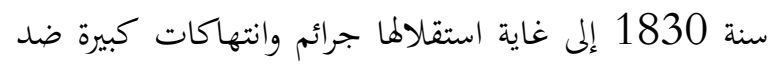

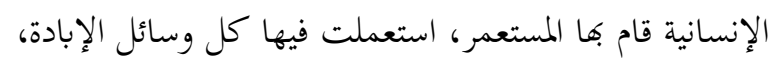

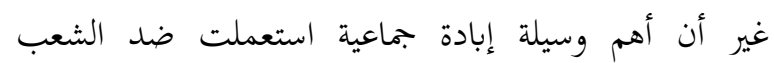

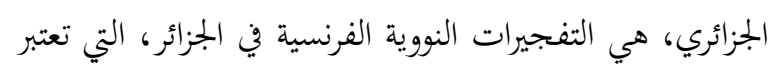

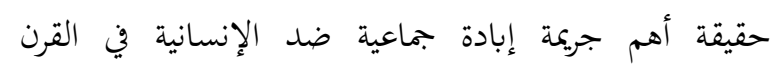
العشرين، وهي تجارب لأسلحة دمار شامل نووية وكيميائية وصواريخ باليستية قامت بها فرنسا في عدة مواقع من الصحراء

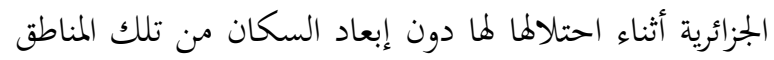
أو تحذيرهم، إذ كان أول تفجير نووي بمنطقة "رقان" في 13 فيفري 1960 التي أسميتها بـ " اليربوع الأزرق"، وبهذه تونه

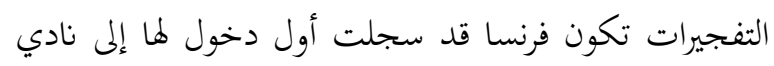

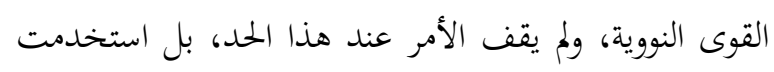
150 سجينًا من المساجين الذين اعتقلتهم، وعلقتهم بألواح النقاح 
3. نتائج الإبادة الجماعية النووية الفرنسية بالجزائر، وآثارها المدمرة في الإنسانية.

4. المطالبة بالتعويض الفرنسي عن جرائم الإبادة الجماعية النابتحة عن التفجيرات النووية في الجزائر.

\section{1- 1 واقع وحقيقة جرائم الإبادة الجماعية النووية}

\section{الفرنسية في الجزائر}

رغم كل جرائم الإبادة والتقتيل والتعذيب التي مارستها

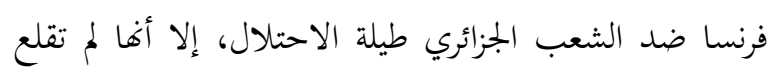

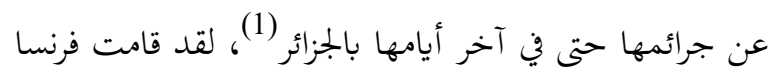
بالتجارب النووية يصح أن نسميها بالجرائم النووية في الصحراء

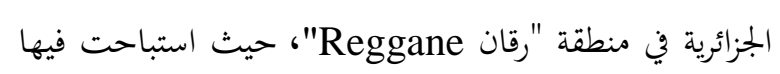
حرمة الأرض والإنسان (2)، تحت إشراف مباشر من الرئيس

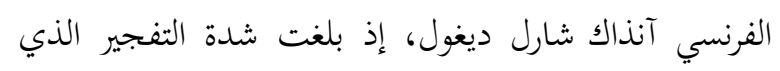

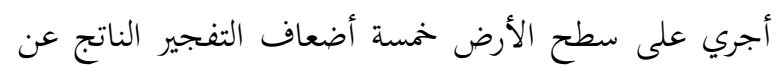

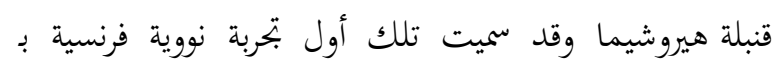

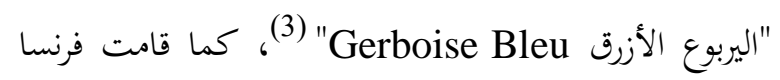

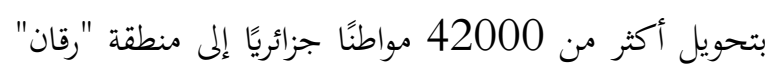

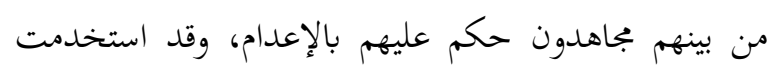

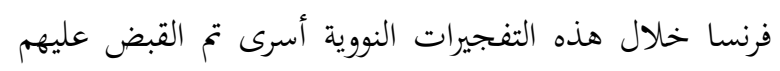

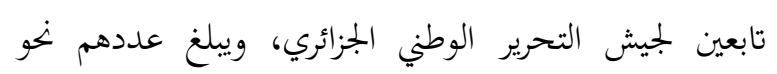

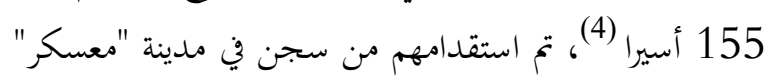

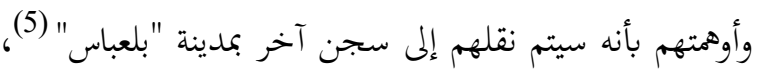

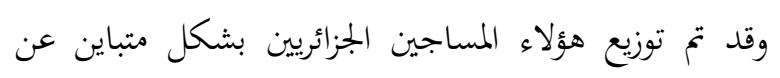
نقطة الصفر (نقطة الانفجار) لمعرفة الدرجات المختلفة لتأثير

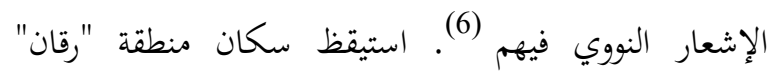

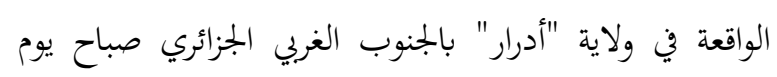

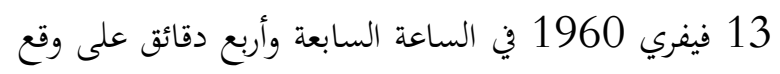

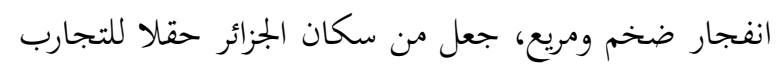

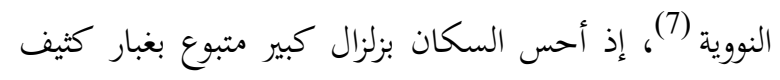
مع وميض ضوئي يمكن رؤيته من منطقة "كرزاز" بولاية "بشار" على بعد 650 كلم من منطقة الانفجار، ولقد مؤينه من منطة كرزاز بولية
إشكالية البحث: تتمثل إشكالية موضوع البحث في ما يلي:

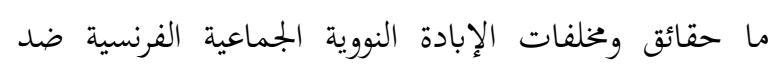
الشعب الجزائري؟ فرضية البحث: لقد كانت لجريمة الإبادة النووية الجماعية

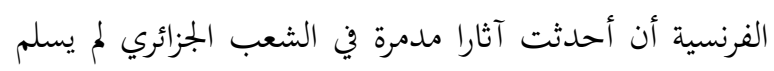
منها أي كائن حي، التي بينت فظاعة تلك الجرائم النكراء.

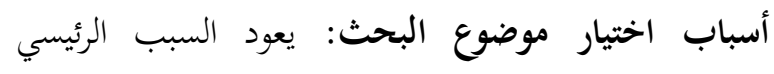

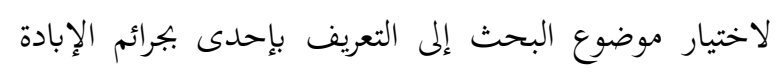

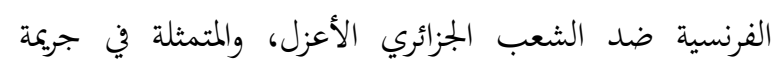

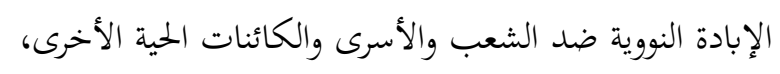

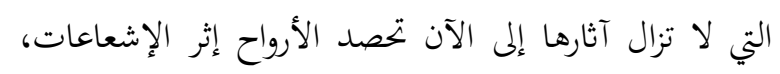

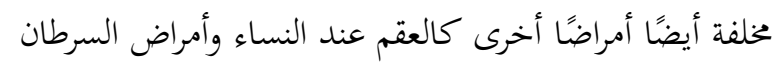

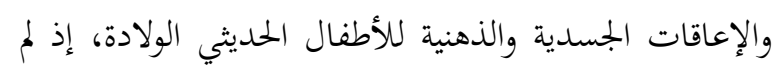
تكن الكتابات والبحوث تشير إلى ذلك إلا منذ سنة 2000

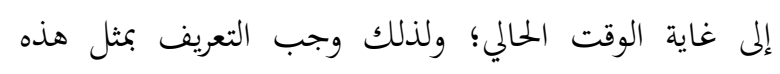
الجريمة ومقاضاة فرنسا عليها وتعويض الضحايا الذين يعانون

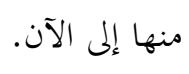
منهجية البحث: لقد تم الاعتماد على توليفة من المناهج كمثل المنهج التاريخي، الذي أستخدم لمعرفة أحد الأحداث التي جرت في الماضي خلال الفترة الاستعمارية الفرنسية للجزائر بقصد دراسة وتحليل المشكلات الإنسانية التي أحدثثها تلك الوقائع التاريخية، وكذا المنهج الإحصائي والمنهج القانوني، اللذان يخدمان موضوع البحث. هيكلية البحث: سنحاول من خلال هذه المشاركة البحثية معالجة موضوع: "التفجيرات النووية الفرنسية في الجزائر كأحد أهم نماذج جورائم الإبادة الجماعية في القرن العشرين"، ولإجابة عن ذلك سنتناول المباحث التالية:

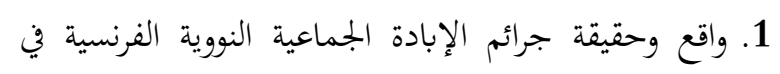
الجزائر. 2. ردود الفعل العربية والدولية بخصوص تفجيرات الإبادة الجماعية النووية الفرنسية في الجزائر. 
المشينة انتهائًا صارخًا لكل مبادئ القانون الدولي والقيم الإنسانية وحقوق الإنسان.

وعن تمدد الإشعاعات النووية، فعقب بتربة "اليربوع الإسطان

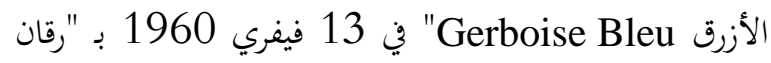
Reggane التلوث الإشعاعي في حيز ضيق من الصحراء الجزائرية، إلا أنه عند نشر الخرائط الحقيقية - بعد إخراجها من دائرة أسرار الدفاع - سنة 2013 تبين أن الغبار النووي قد طال أرجاء واسعة من منطقة الساحل الإفريقي وصولًا إلى إفريقيا الغربية

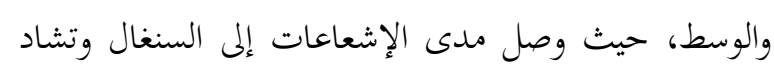

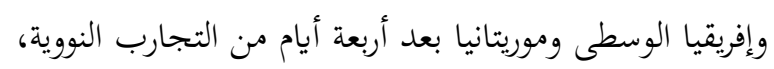

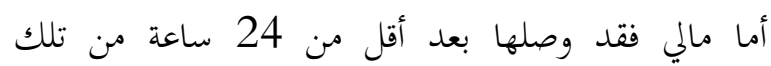
التفجيرات (13).

\section{2 - ردود الفعل العربية والدولية بخصوص تفجيرات الإبادة الجماعية النووية الفرنسية في الجزائر}

لقد أثارت التفجيرات النووية في رقان صدى كبيرًا لدى الأوساط الدولية وكانت لها ردود أفعال متباينة نذكر منها: 1 - العراق: نقل راديو بغداد (إذاعة بغداد) عن وكالة

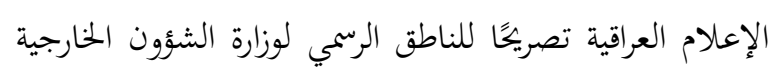
العراقية جاء فيه ما يلي: "إن التجارب النووية التي أجرتحا

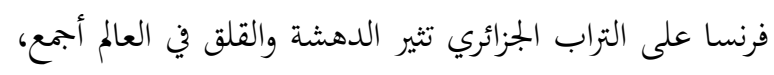

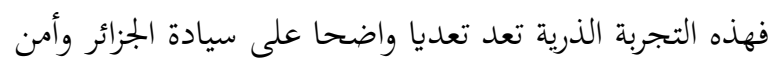

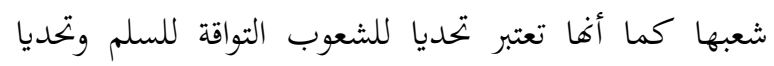

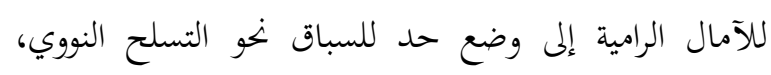

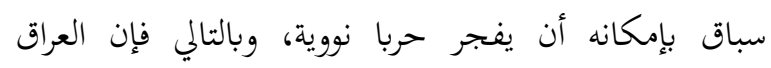

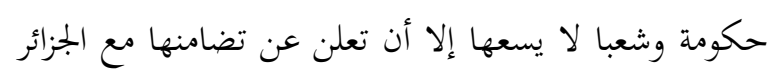
حكومة وشعبا وأن يقف معها في كل الخطوات التي تراها ضرورية من أجل الدفاع عن أمنها وتقوية سيادتا" (14).

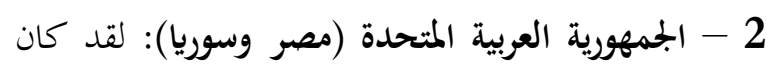

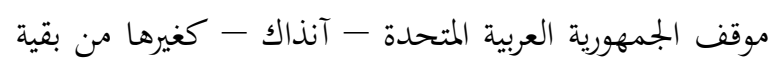

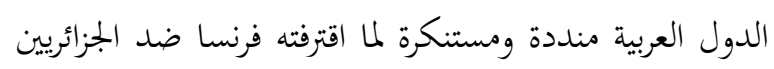

استمر ذلك الدخان والغبار حتى منتصف النهار، ثم اتجهت

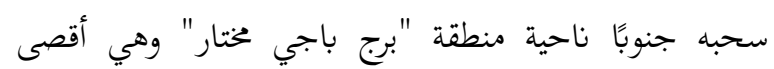

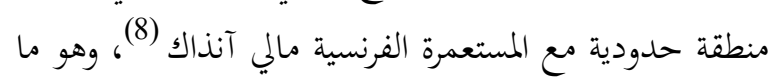

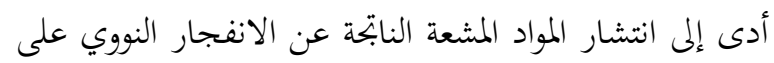

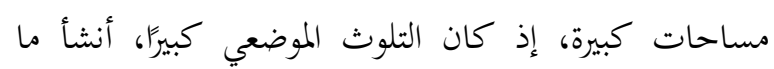
يسمى بـ "الغمر القاعدي" الذي يبلغ مداه خمسة أميال

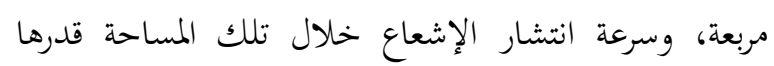
خمسون ميلا في الساعة (9). وقبل أسبوع من يوم التفجيرات عمدت السبات السلطات

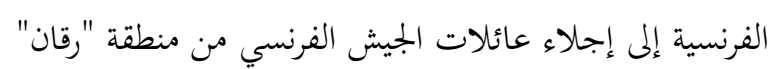

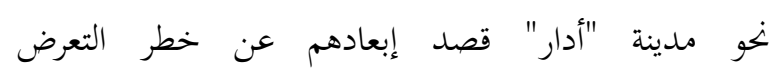
للإشعاعات النووية، رغم تعمدهم تعريض سكان ادران منطقة "رقان" لذلك الخطر غير مبالين بالقوانين والأعراف الدولية ولا

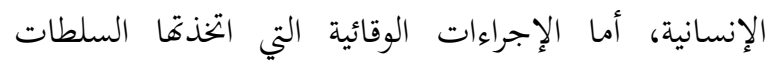

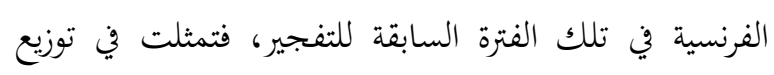
النظارات السوداء والملابس الواقية على المجندين الفرنسيين دون الجزائريين بالقاعدة العسكرية الفرنسية بـ "رقان Reggane"

ولقد تم سماع دوي الانفجار ورؤية ضوئه في مناطق

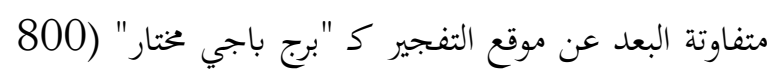

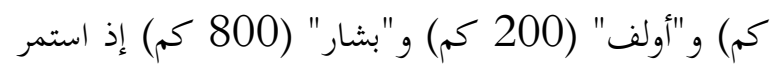

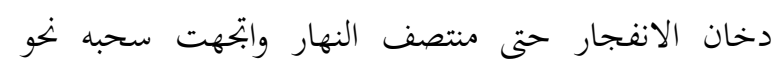
ناحية "برج باجي مختار" الواقع في أقصى الجنوب بمحاذات

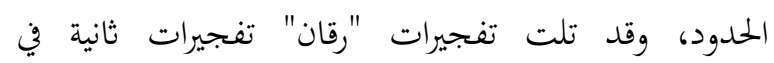

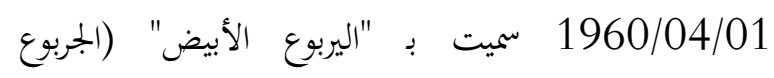
الأبيض)، فجرت بطاقة نحو 10 كيلو طن، ثم تلتها بتربة ثالثة

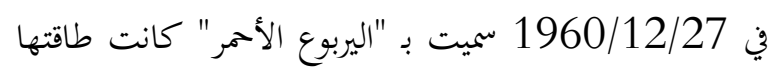

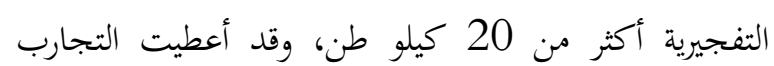
الثلاثة ألوان العلم الفرنسي كحدث مهم في تاريخ فرنسا (11)، فبخروج فرنسا من الجزائر تركت المواقع النووية دون اتخاذ اللازم للحيلولة دون أن تشمل تأثيرات النفايات النووية الإنسان

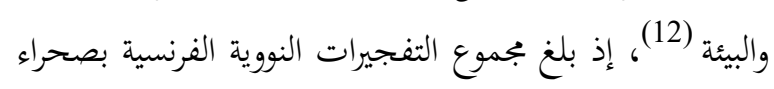

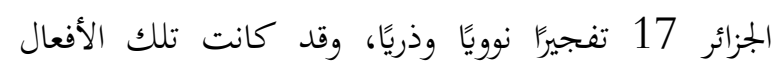


واعتبر الحرب أن فرنسا التي اهزمت تحاول الآن إبادة الشعب

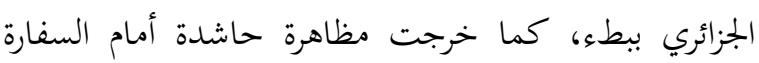
الفرنسية بالعاصمة "كامبالا". 8

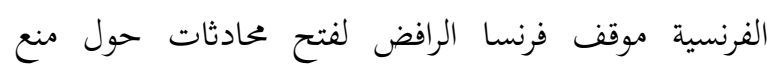
التجارب النووية، وكتبت صحيفة صوت لإثيوبيا "إذا أرادت

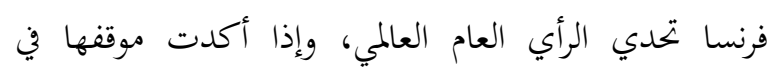

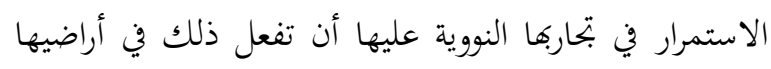

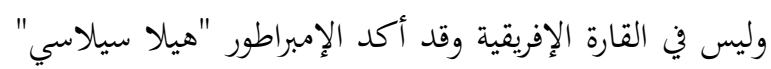

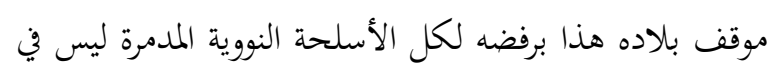
إفريقيا فقط بل في العالم كله (17). 9 - يوغسلافيا: أعلنت مساندقا المطلقة للحكومة الجزائرية المؤقتة، وقد جاء التأييد على لسان رئيس البرلمان والناطق

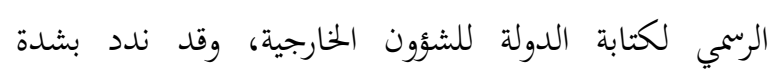
التجارب النووية الفرنسية على الأراضي الجزائرية، كما أكدت لمدئل

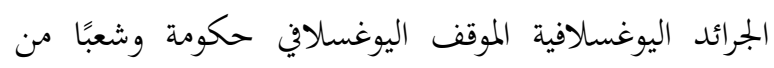

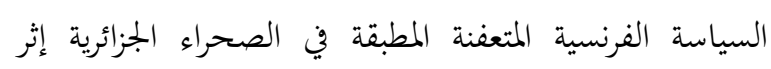

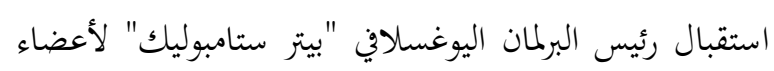

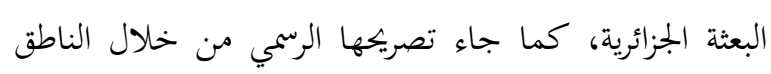

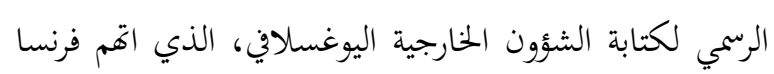

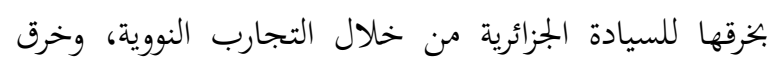

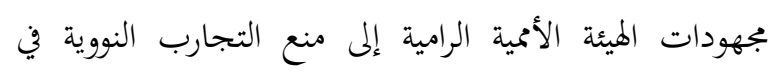
العالم. - (n 10 - الاتحاد السوفياتي: قد عارض هذه التجارب وأعرب عن رفضه القاطع لها، وكتبت وكالة "تاس" السوفياتية ما يلي "لقد قامت فرنسا بتفجير نووي جديد في 18 مارست وكاس

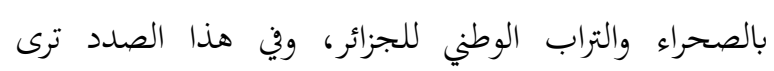
السلطات السوفياتية أن ما أقدمت عليه فرنسا هو تحدٍ للرأي

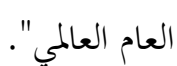
11 - الولايات المتحدة الأمريكية: رحب البنتاغون

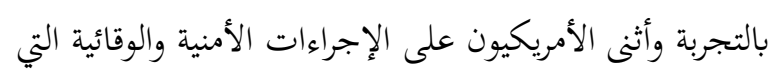

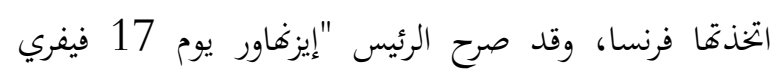

عامة والصحراء بوجه الخصوص، وهذا ما صرح به وزير الثقافة

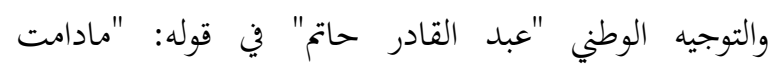
التجارب النووية الفرنسية تشكل عملا عدوانيا واضحا تجاه الجنس البشري في تطلعاته ومستقبله، فلذلك تعتبر خرقا

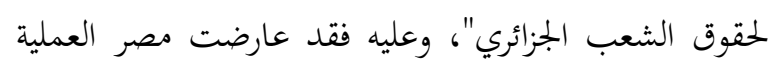
من أساسها أشد معارضة. 3 - ليبيا: قدمت الحكومة الليبية في العاصمة طرابلس مذكرة

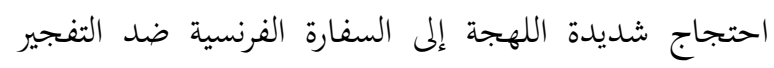

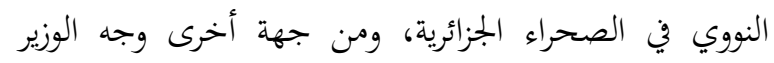

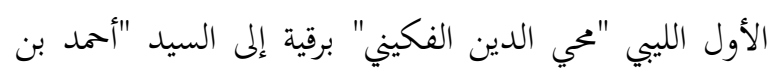

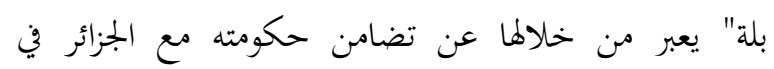
موقفها الشرعي في معارضة هذه التجارب على أرضها (15). 4

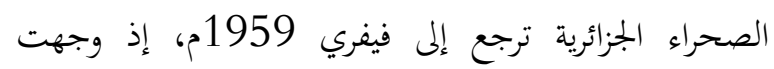
رسائل إلى فرنسا وبقيت دون مفعول مما أدى بها إلى استدعاء إدراء

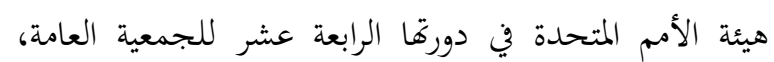

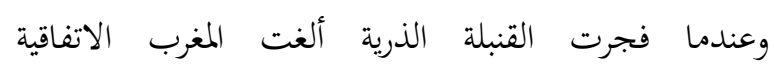

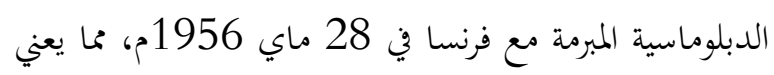

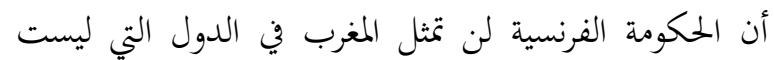
لديها سفارات بها كما تم استدعاء سفير المغرب بفرنسا (16). 5 الفرنسية معرضة للانقطاع في حال استمرار فرنسا في بتحاربها

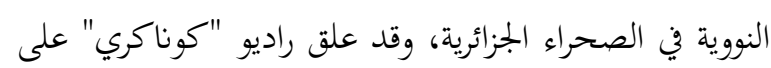

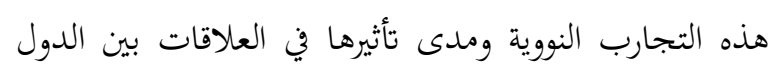
العربية وفرنسا. 6 - غانا: اتخذت قرارًا صارمًا وجريئًا ضد تجربة الإبادة النووية

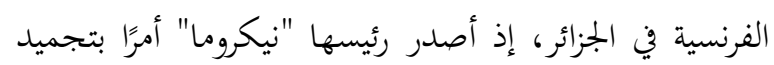
أموال كل الفرنسيين إلى غاية التعرف على نتائج تفجير القنبلة ومعرفة نتائجها. 7 - أوغندا: نظم أهم حزب حكومي وهو وهو "حزب مؤتمر

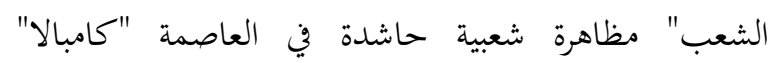
احتجاجًا على التجارب النووية الفرنسية في الصحراء الجزائرية، 


\section{3 - نتائج الإبادة الجماعية النووية الفرنسية بالجزائر،} وآثارها المدمرة في حق الإنسانية

لقد أحدثت فظائع التجربة النووية الفرنسية بـ "رقان" في 1960/02/13 بالجزائر جريكة إبادة جماعية لا تزال آثارها

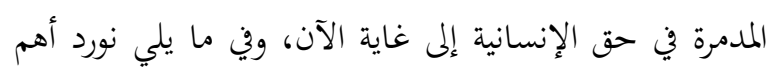
ما خلفته وأحدثته تلك الإبادة:

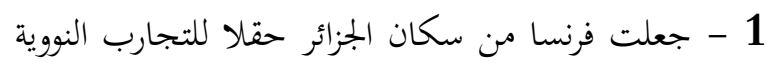

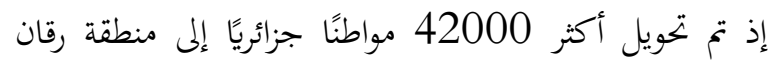
وكذا تحويل بجاهدين حكم عليهم بالإعدام إلى فئران بتحارب.

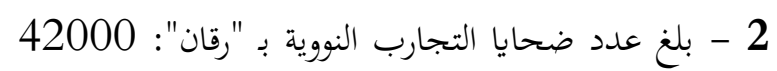

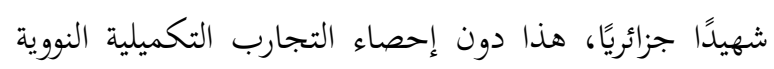
الفرنسية التي بلغت 17 تفجيرا بالجزائر. 3 تفجير "هيروشيما" بـ 5 مرات.

4 - معاناة سكان المنطقة من الإشعاعات النووية لفترة تزيد

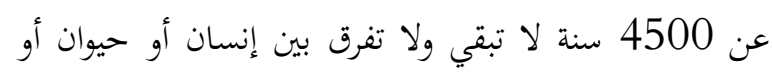
نبات. 5 - تعريض 150 أسيرً جزائريًا لأول تفجير نووي بـ "رقان"،

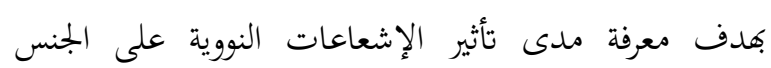

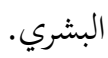
6 - إحداث سحابة مشحونة بعناصر مشعة نتجت عن هذه التجربة الأولى وصلت إلى غاية "نيامي" بالنيجر وكان نشاطها الإثعاعي أكثر من وصن الألت 100000 مرة من معدلها العادي. 7 - 7 - انتشار العقم في أوساط النساء. 8

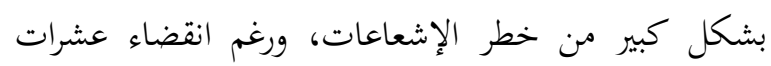

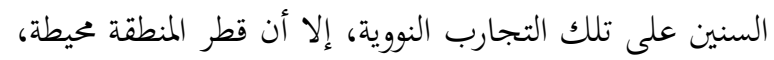

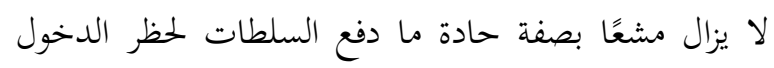

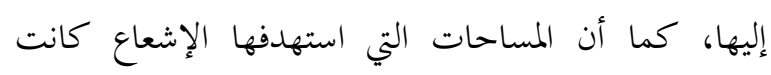
شاسعة وأكبر من المتوقع ومتداخلة التأثيرات. 9 - التشوهات الملقية المستفحلة لدى المواليد الجدد، كصغر
1960م في ندوة صحفية بأن التجربة الفرنسية أمر طبيعي، فني الأول قامت بريطانيا بتجربتها النووية ثم تلتها فرنسا وليس هنالك ما يضر، وقد أعرب عن أمله في أن تتوصل

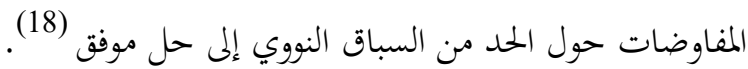

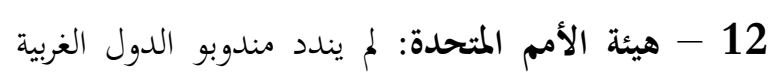
هذه التفجيرات بل كان هناك تأييد حكومي من طرف أعضاء

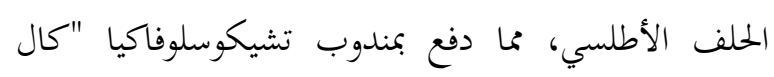
Karel

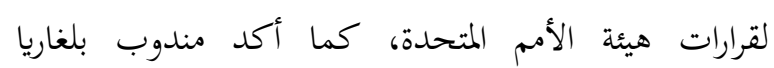
"ميلكوترابانوف" أن تفجير القنبلة في الصحراء الجزائرية شاهد المداب

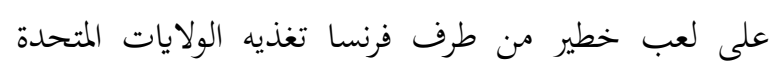
الأمريكية، إذ تشجع فرنسا على التمادي فيه، أما أكثرية الدول التي قد أدانت التفجيرات فهي الهند، إثيوبيا، بولونيا، كندا والاتحاد السوفياتي (19)، ولقد أثار قرار هيئة الأمم الثمان

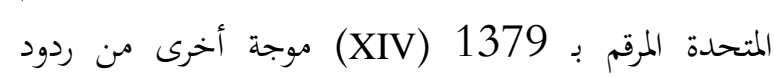

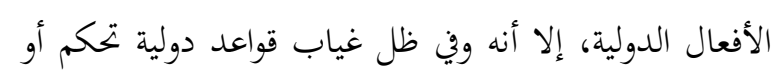

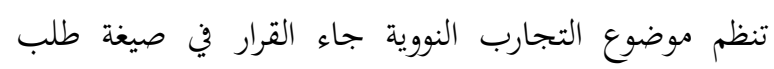

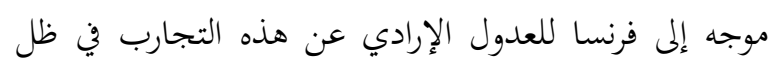

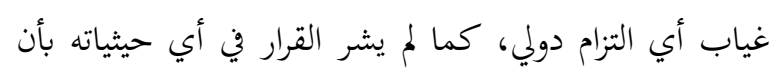

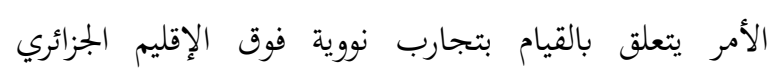

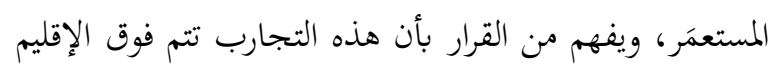

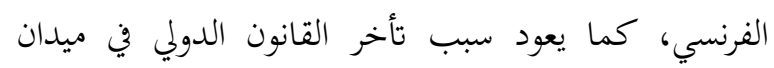
تنظيم التسلح النووي إلى عدم رغبة واستعداد الدول النووية في الني

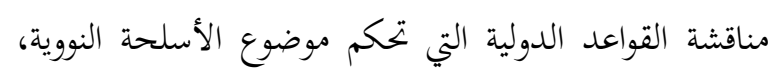

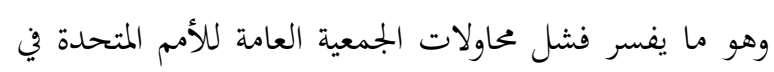
تطوير القانون الدولي في بحال الاستخدام العسكري للأسلحة

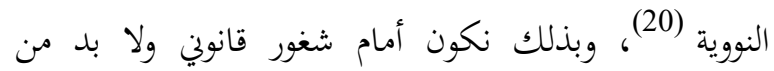
التأسيس لتكييف قانوين يسمح بمنح صفة الجزرم الدولي لفرنسا

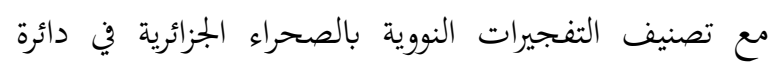
جرائم ضد الإنسانية وجرائم الإبادة الجماعية (21). 
الرئيسي للكثير من الأمراض السرطانية وأمراض القلب والشرايين بالمنطقة"، واصفًا سلسلة التفجيرات النووية الفرنسية بتجارب الإبادة حيث تم استعمال سكان المنطقة كفئران

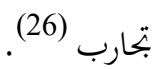
ففي أول إحصاء طبي جزائري أجري عام 1990م على

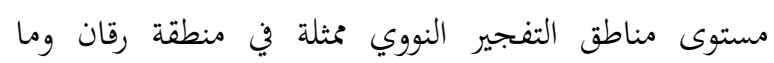

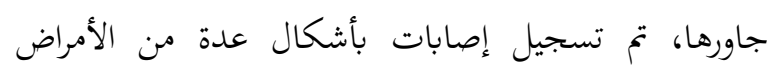

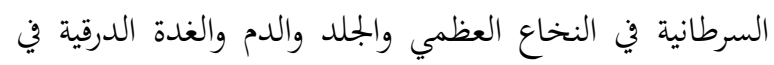

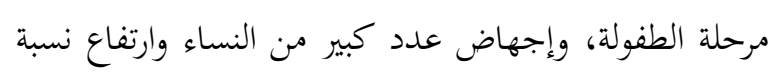

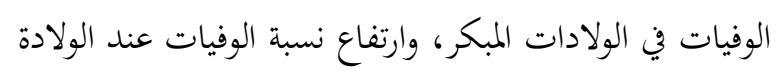
وتساقط الشعر، وزيادة نسبة الصم والبيكم والمتخلفين ذهنيا، كما سجلت الملاحظات الطبية أمراض العجز الكلوي الناجمة ولمبه عن التعرض للإشعاع النووي (27). 14 - كما أن نأثير الانفجار قد جعل من المكان التفوي لهنيري

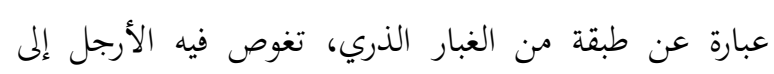

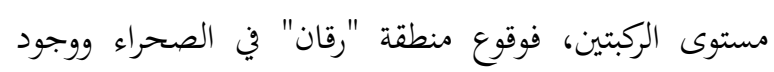

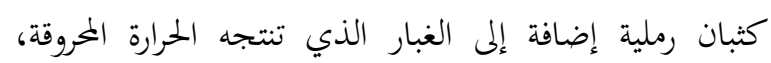

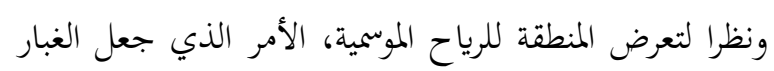

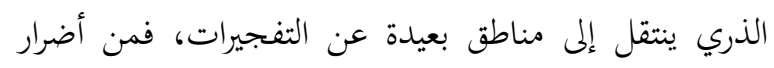

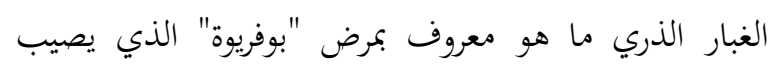

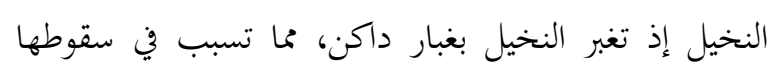

$$
\text { قبل نضجها. }
$$

15 - احتراق العديد من الغابات الصحراوية التي كانت بالمنطقة، وارتفعت درجة حرارة المنطقة مما أثر بيئيا عليها، فهاجرت العديد من الحيوانات التي كانت تعيش هناك.

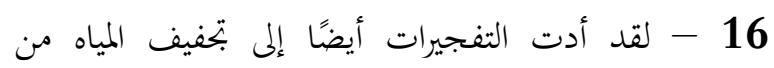

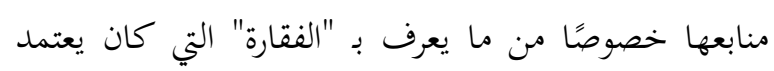

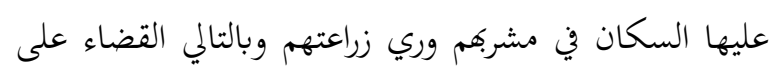
المورد الاقتصادي لسكان المنطقة (28). 17 - استخدام السكان كفئران بحارب، فقبل أربعة أشهر لمان الشعان من التفجير قامت السلطات الاستعمارية الفرنسية بعملية

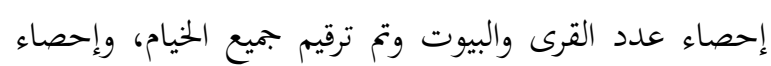

10 - زوال مظاهر فصل الربيع في المناطق التي خضعت للتجارب. 11 - تلوث آبار المياه، إذ أدت التفجيرات النووية إلى تلوث

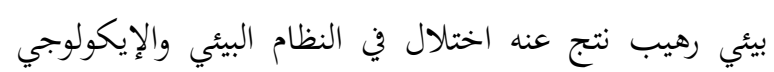
(22)، وأدت الإشعاعات إلى انخفاض في التنوع الإحيائي

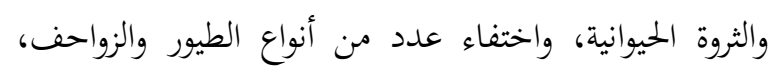

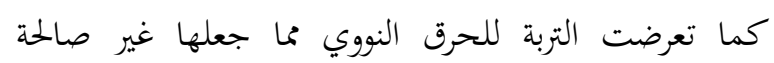
للزراعة فتدهور الغطاء النباتي وانخفض إنتاج المحاصيل الزراعية فيما تعرضت المياه السطحية والجوفية للتلوث الإشعاعي (23).

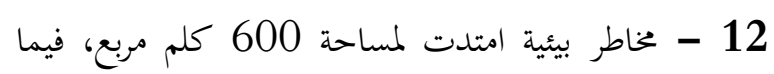
تسببت النفايات وبقايا التفجير في إبادة 60 ألف جزائري بين

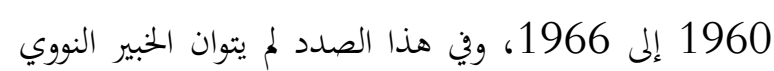

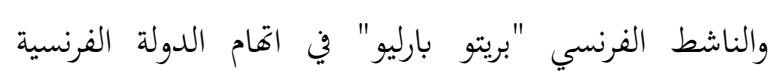
باقتراف جريمة ضد السكان بعد وقوفه على طريقة ردم

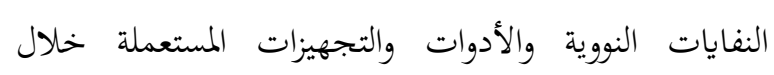
التجارب النووية بكيفية سطحية بحيث لم تتبع القواعد العلمية في ذلك (24). 13 - تفشي أمراض السرطان وأمراض أخرى خطيرة وقاتلة،

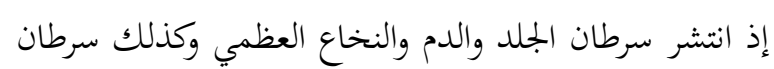

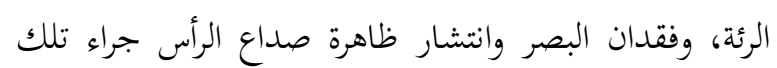
الاشعاعات النووية التي حدثت إثر التفجيرات النووية (25)،

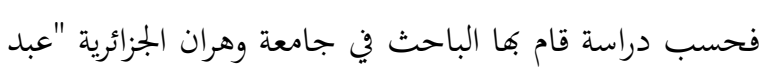
الكاظم العبودي" فقد أثبت من خلال دراسته "التجارب النووية الفرنسية وأخطار التلوث الإشعاعي على الصحة والبيئة

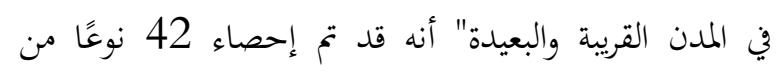
السرطان إذ أوضحت الإشعاعات النووية والتلوث الإشعاعي

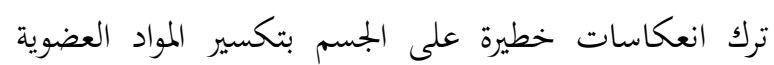
والخلايا والتأثيرات في الجينات الوراثية مما سبب التشوهات التبات الخلقية وهي تصيب الكروموزومات، وخصوصًا لدى الأطفال

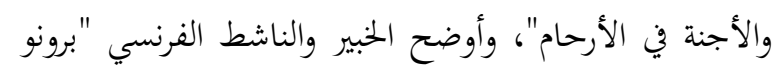

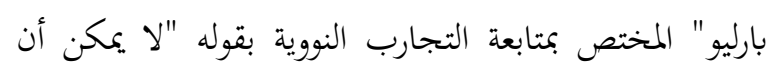

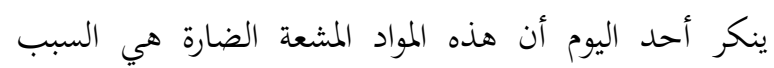


فالمادة الثانية مثلا من اتفاقية منع جريمة الإبادة الجماعية والمعاقبة عليها لسنة 1948 قد نصت على أفعال تدخل

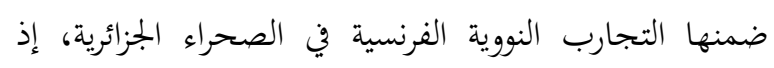

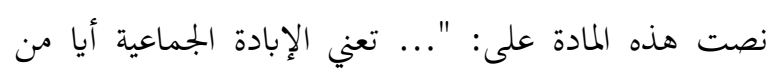

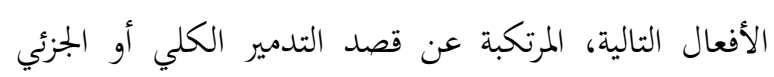

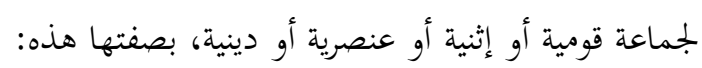
1. قتل أعضاء من الجماعة.

2. إلحاق أذى جسدي أو روحي خطير بأعضاء الجماعة. 3. إخضاع الجماعة عمدا لظروف معيشية يراد بها تدميرها المادي كليا أو جزئيا..." (33).

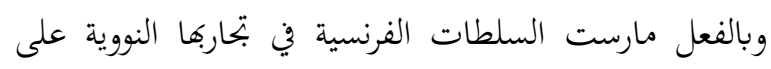
الصحراء الجزائرية الانتهاكات المذكورة في المادة الثانية السابقة

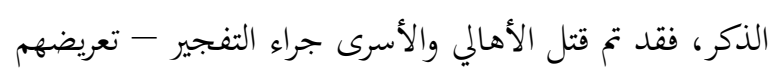

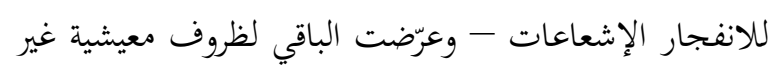

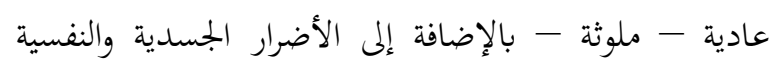
الكبيرة (34) ملونة بالإضافة إلى خروقات التجارب النووية الفرنسية في الجزائر

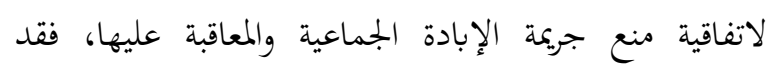

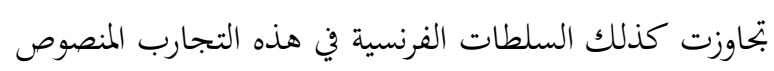

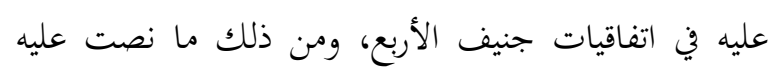

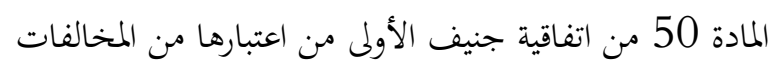
الجسيمة - القيام بالقتل العمد والتعذيب أو معاملة لا إنسانية بما في ذلك التجارب الخاصة بعلم الحياة، وتعمد إحداث آلام

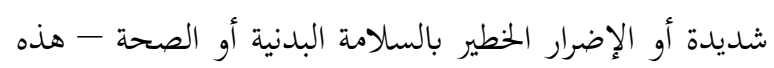

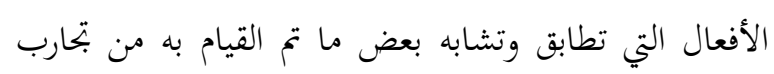
نووية فرنسية في الصحراء الجزائرية (35). غير أن السطات الفرنسية كما سبق التنويه له سابقًا لم الم

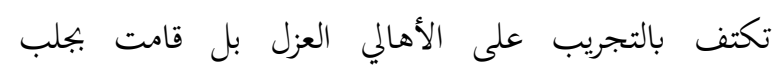

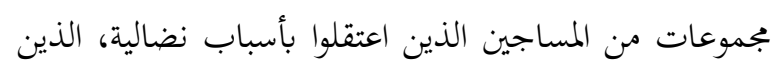

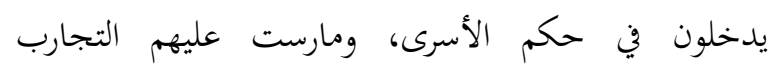
بتعريضهم لخطر الإشعاعات، ما يعتبر مخالف للمادتين 19

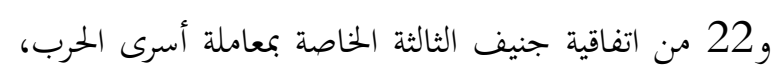

البشر والحيوانات والأشجار والنباتات كما تم توزيع قلائد

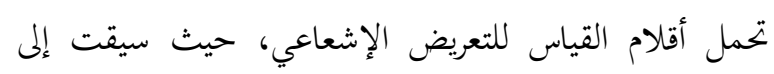

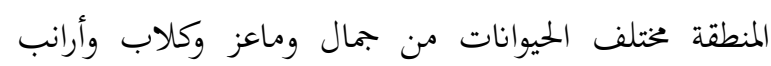

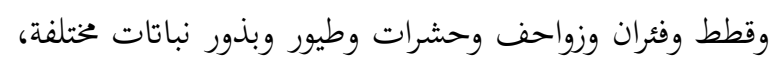

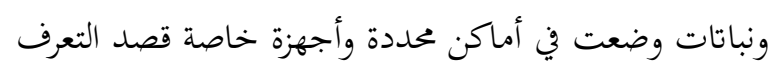
على تأثير الإشعاع خلال وبعد تفجير القنبلة، إذ يقول "الحاج

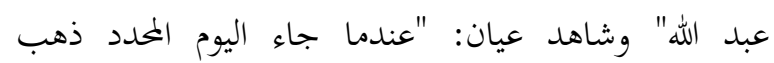
الفرنسيون إلى البيوت وأماكن تواجد الناس وراحوا يعلقون لهم

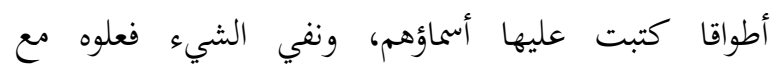
الحيوانات، والمدف من ذلك التعرف على جثث الضحايا وأماكن تواجدها قبل وبعد الانفجار " (29). 18 - حدوث التلوث الإشعاعي للتربة، إذ يعتبر التلوث

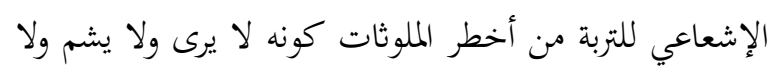
يمكن الإحساس به، وخير مثال على ذلك تلوث مناطق كبيرة

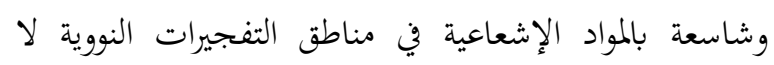

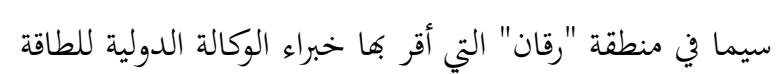

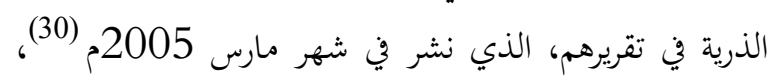

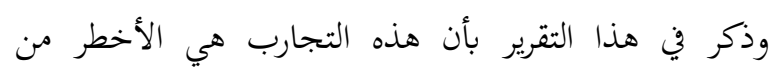
نوعها، وأن الإشعاعات ما تزال قوتما ضارية في صحراء

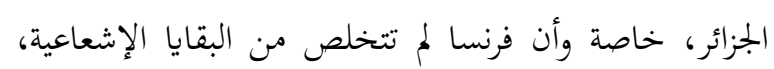

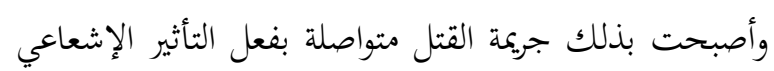
المتواجد بالمناطق المتضررة (31).

\section{4 - المطالبة بالتعويض الفرنسي عن جرائم الإبادة الجماعية الناتجة عن التفجيرات النووية في الجزائر}

إن إنجارب النووية الفرنسية في الجزائر التي وجهت على

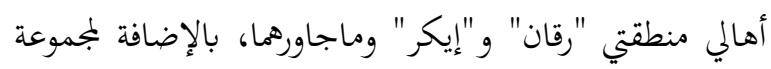

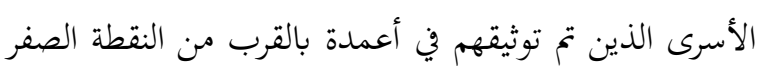

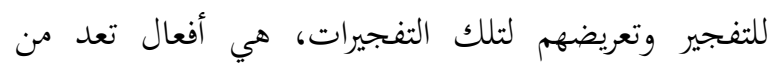

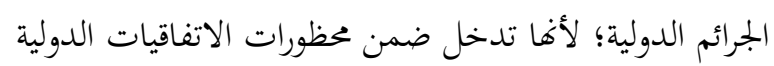

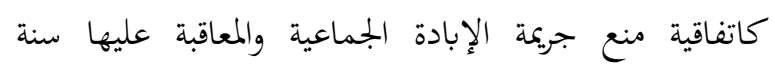
1948 واتفاقيات جنيف الأربع (32). 
المؤرخ في 1993/06/16 والمتعلق بالمسئولية عن الانتهاكات الجسيمة للاتفاقيات الدولية لجنيف 1949 وبروتوكولاتها الأول والثاني، حيث أعطى هذا القانون للقضاء

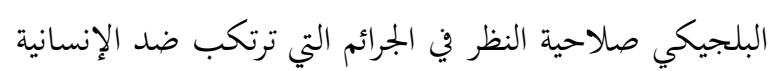

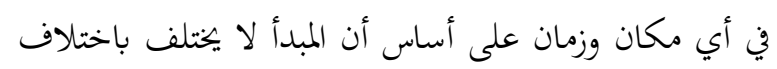

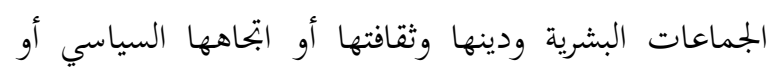
الفكري وغيره (37). وتعتبر المادة السابعة من قانون 1993/06/16 النص وغره الصريح عن اختصاص القضاء البلجيكي اختصاصًا عالميًا في الئي

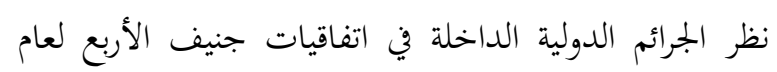

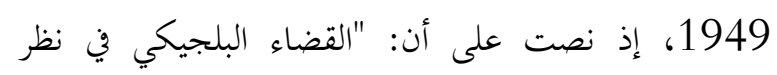
الانتهاكات الجسيمة في 1993/06/16 والتعلق بالمسؤولية عن الانتهاكات الجسيمة للاتفاقيات الدولية لجنيف 1949

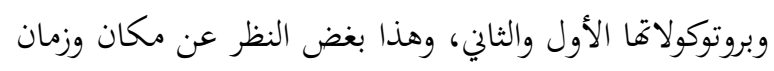

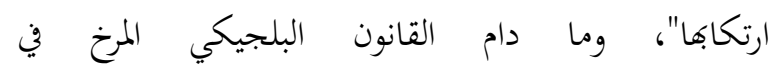

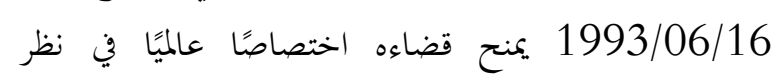

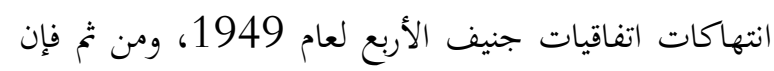

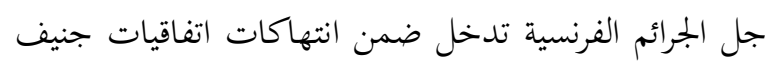

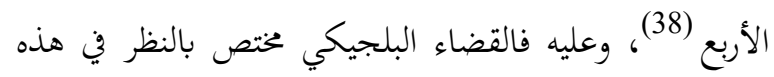

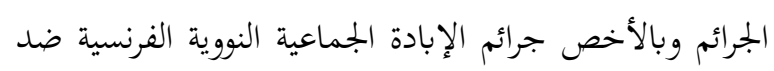
الشعب الجزائري.

أما من حيث عرض القضية على القضاء البلجيكي فهناك

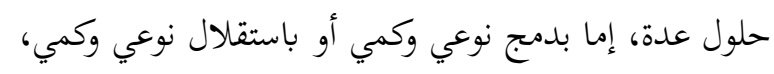

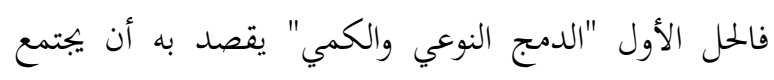

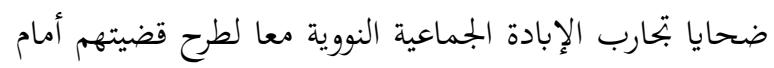

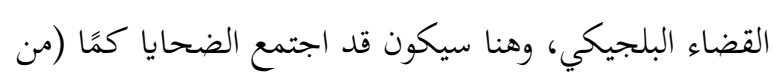

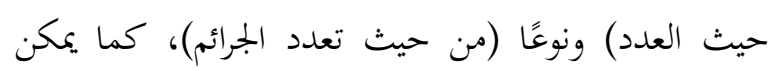

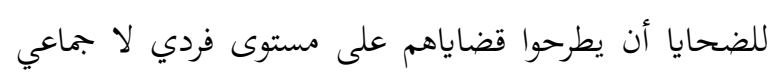

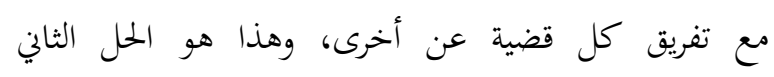

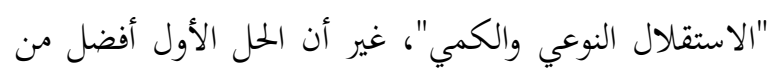

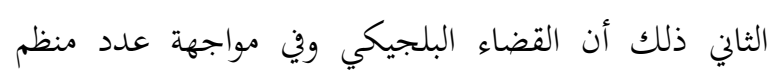

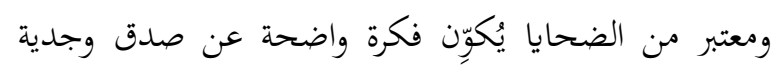

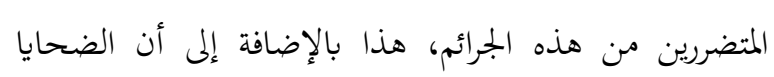

التي تقضي بإبعاد الأسير عن الخطر، إذ نصت المادة 19 على

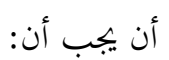
"يتم إجلاء أسرى الحرب بأسرع ما يمكن بعد أسرهم...

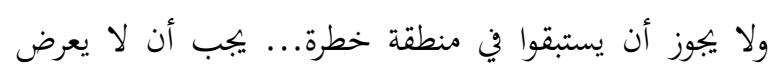
أسرى الحرب للخطر دون مبرر..."، والإشعاعات النووية تعتبر

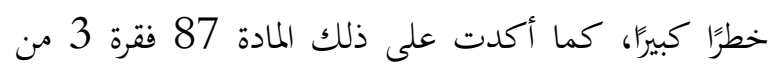
نفس الاتفاقية حين نصت: نفس الاتفافية حين نصن: ... تحظر العقوبات الجماعية عن أفعال فردية، والعقوبات البدنية، والحبس في مبانٍ لا يدخلها ضوء النهار،

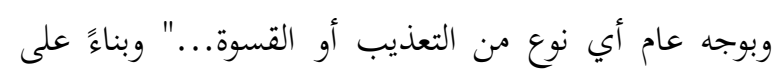

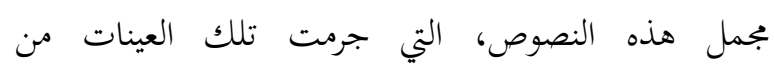

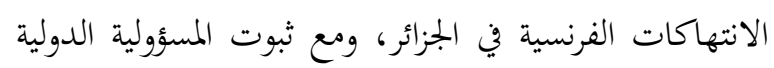

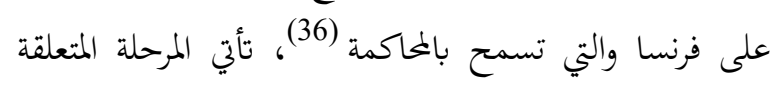

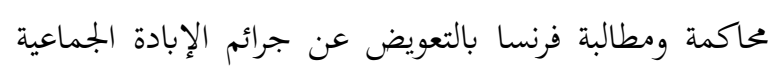
النابتحة عن التفجيرات النووية في الجزائر. يمكن أن تتجسد فرص محاكمة فرنسا على جرائمها

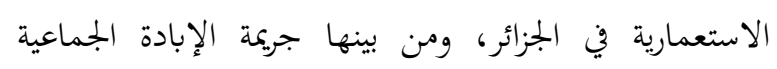
النووية ضد الجزائريين وذلك من خلال اعتماد فجين: 4.1 - المحاكمة بواسطة المحاكم الوطنية ذات الاختصاص العالمي (القضاء البلجيكي)

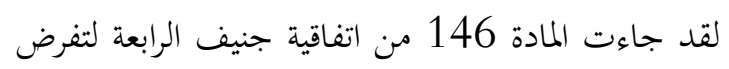
على الدول الأطراف فيها بأن يتخذوا من الإجراءات التشريعية

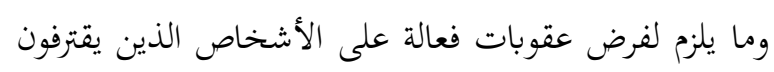

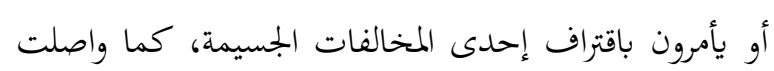
المادة كذلك بإلزام أطراف الاتفاقية بملاحقة المتهمين باقتراف أو الأمر بالمخالفات الجسيمة، وبتقديمهم للمحاكمة أيًا كانت

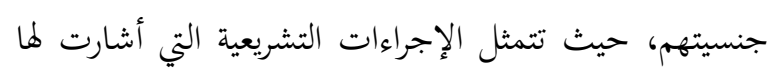

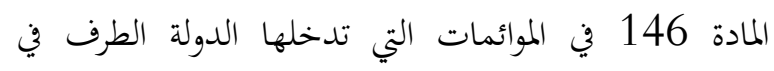
الاتفاقيات إلى مختلف قوانينها (الدستور، التشريع، التنظيم) قصد جعل محاكمها الوطنية مختصة في مثل هذه الانتهاكات الجسيمة الدولية المنصوص عليها في اتفاقيات جنيف الأربع،

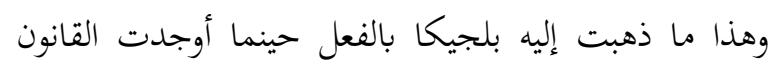


يكون إيجابيًا بالموافقة إذا واجهت فرنسا ضغطًا دوليًا وداخليًا،

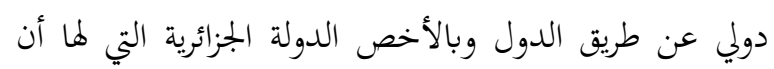

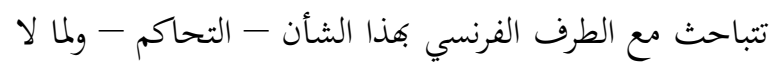
الوصول إلى قانون فرنسي يجرم الأفعال الفرنسية في الجزائر

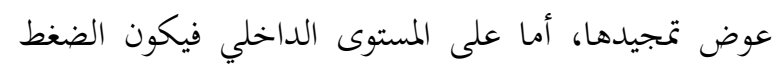
بواسطة مختلف أطياف المجتمع الفرنسي من سياسيين وباحثين وحقوقيين، بالإضافة إلى الدور الهام للمجتمع المدني بهذا الخصوص، وخير دليل على إمكانية تغيير التوجهات السياسية بلهية

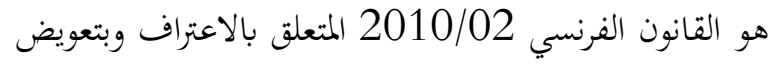
ضحايا التجارب النووية الفرنسية المؤرخ في 2010/01/05، وهي التجارب التي تربت فرنسا لسنوات من نتائجها الوخيمة

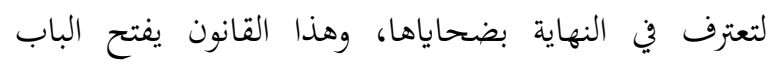
لضحايا تجارب الإبادة الجماعية النووية الفرنسية في الصحراء

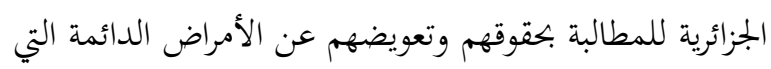

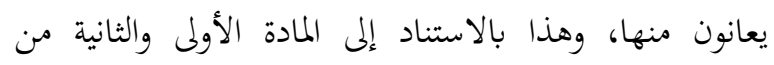
القانون 2010/02 اللتين نصتا صراحة على المواقع الجغرافية والفترات الزمانية للتجارب النووية الفرنسية في الصحراء الجزائرية (42). إن اعتراف فرنسا بجرائم الإبادة ضد الشعب الجزائري من

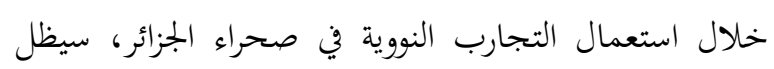

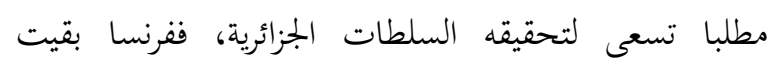

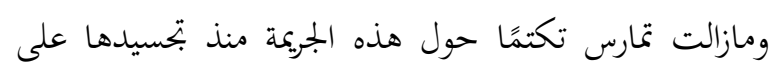
الواقع بحجة أن العلم بمجريات هذه التجارب يعتبر هساسًا

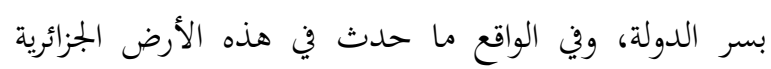
يعتبر وصمة عار في جبين فرنسا والفرنسيين وكل من هم في

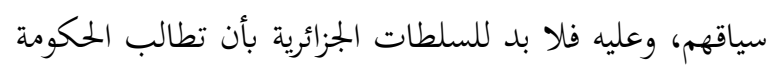

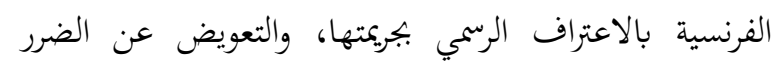

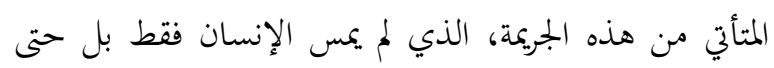

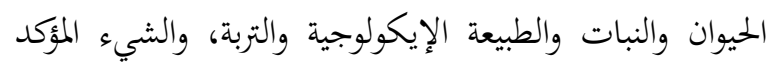
هو أن أي تعاطف أو تعويض لن يكفي بلمو آثار الدمار

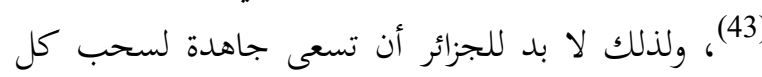

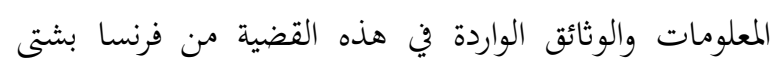

باجتماعهم سيكون عملهم ونشاطهم أكثر عملية وفعالية، الأمر الذي سيؤثر كذلك في جانب التمثيل القانوني أين يمكن

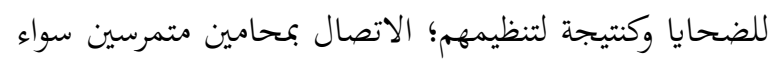

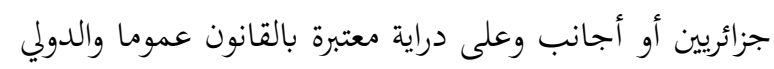
خصوصًا وهذا لتمثيلهم أمام القضاء البلجيكي (39). 4.2 - المحاكمة بواسطة محاكم دولية جنائية خاصة:

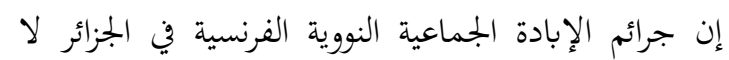

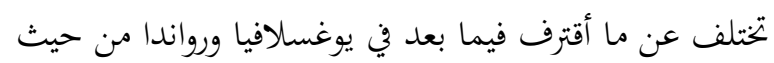

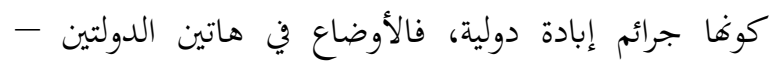

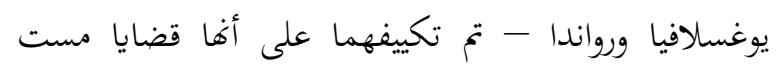

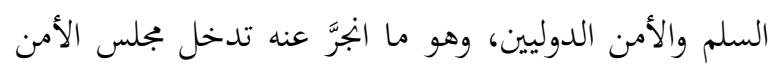

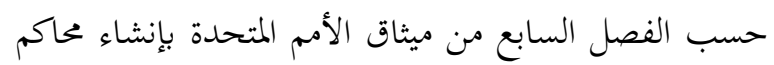

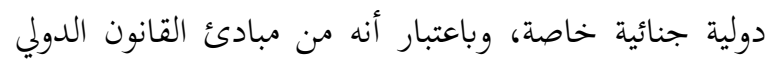

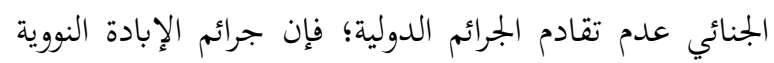

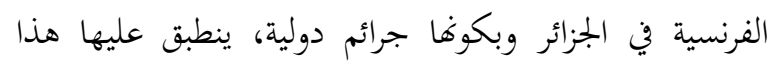

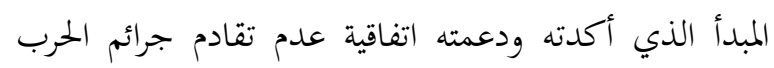
والجرائم ضد الإنسانية عام 1968، وبذلك فإنه من الممكن إنشاء محكمة أو محاكم دولية جنائية خاصة لما وقع في الجزائر من جرائم فرنسية (40). غير أن إمكانية إنشاء محاكم دولية جنائية خاصة في حالة الجرائم الفرنسية في الجزائر صعبة نوعا ما، ذلك أن قرار إنشاء

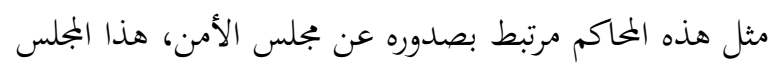

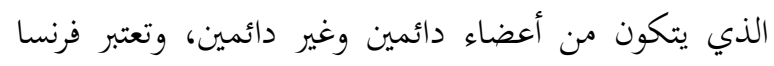

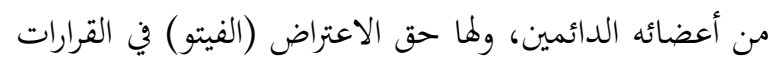

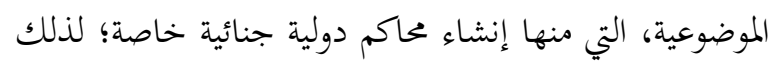
فإن احتمال اعتراض فرنسا عن إنشاء محكمة دولية جنائية خاصة بجرائمها في الجزائر وخاصة جرائم الإبادة الجماعية النووية، أمر وارد بنسبة كبيرة جدا (41).

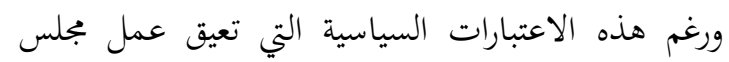
الأمن وتعطل مسائل أخرى مرتبطة به، كإنشاء المحاكم الدولية

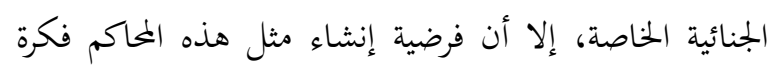

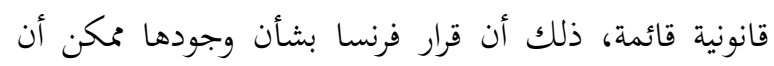


التعويض عنها وتقديم كل الوثائق التي تبين أمكان وجود

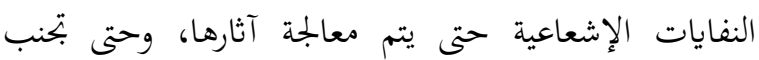

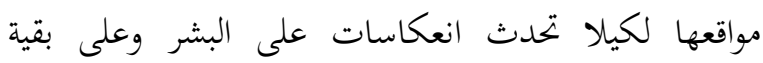
المخلوقات خاصة في ظل الصحراء الجزائرية الشاسعة، إذ يصعب الكشف عن تلك المواقع إلا من خلال الوثائق الفرنسية.

(1) صباح مريوة، "جرائم الحرب النووية في الصحراء الجزائرية: التجربة

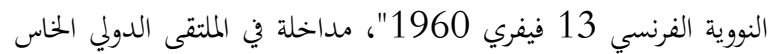

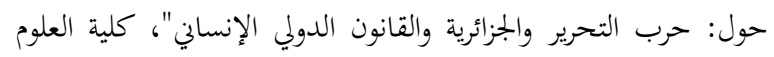
القانونية والإدارية، جامعة حسيبة بن بوعلي، الشلف، الجزائر - أيام

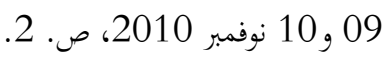

(2)شوقي سمير، "جرائم الاحتلال الفرنسي في الجزائر على ضوء الأعراف

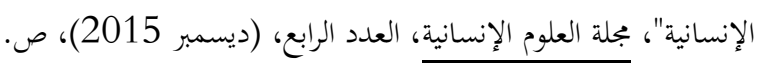

(3) (التجارب النووية الفرنسية بالجزائر.. المأساة المنسية"،

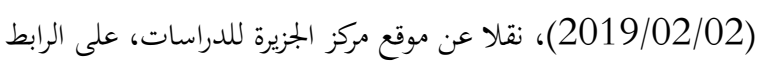

(5) 11. (5) (5مال قبايلي، "التفجيرات النووية الفرنسية في الصحراء الجزائرية، جريكة

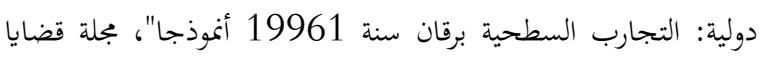

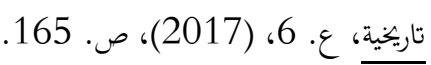
ج) في الجزائر وفق أحكام القانون الدولي الجنائي"، مجلة دفاتر السياسة والقانون، ع. 8، (جانفي 2013)، ص. ص. 72.

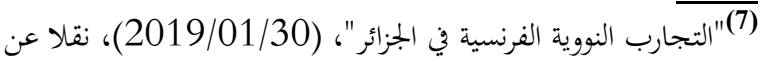

https://bit.ly/3nfiGeT الرابط التالي (8) خير الدين شترة، "الإطار التاريخي للتجارب النووية الفرنسية بالجزائر:

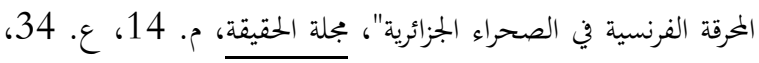

$$
\begin{aligned}
& \text { (سبتمبر 2015)، ص. } 53 . \\
& \text { (9) نفس المرجع، ص. } 55 . \\
& \text { (10) نفس المرجع، ص. } 50 . \\
& \text { (11) (نفس المرجع، ص. المرجع، ص. } 55 .
\end{aligned}
$$

ولا تتأتى هذه الخطوة إلا من خلال رفع اللبس عن السر

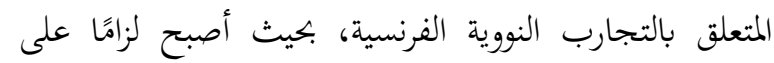
السلطات الجزائرية مناقشة موضوع رفع السر العسكري أو سر سروبه الدفاع عن الموضوعات المتعلقة بالنفايات والإشعاعات النووية؛ لأن الأمر لا يتعلق بالاطلاع على أسرار عسكرية للجيش

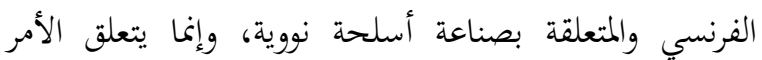

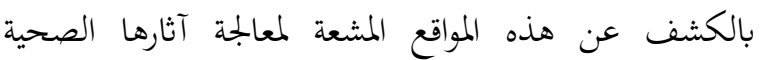
والبيئية؛ ولأن آثار الإشعاعات النووية ما زالت قائمة ومستمرة إلى غاية اليوم؛ فإن الكشف عن مدافن بقايا المواد المشعة

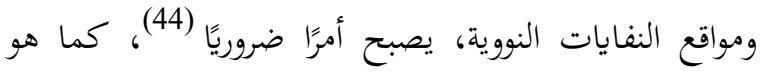
الحال في المطالبة بالتعويضات الملائمة من فرنسا للأضرار التي

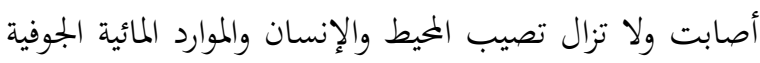
بالصحراء، وكذا التعويض الاقتصادي والمادي لسكان المناطق المتضررة من الإشعاعات لحرماهم من استغلال هذه الموارد الطبيعية في تلك الفضاءات الملوثة (45).

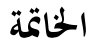

لقد ارتكبت فرنسا ضد الشعب الجزائري جرائم إبادة لا

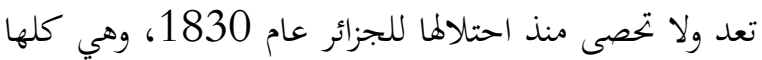
جرائم في حق الإنسانية، استعملت فيها كل وسائل الإبادة،

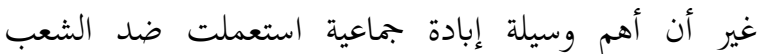
الجزائري، هي التفجيرات النووية الفرنسية في الجزائر، التي تعتبر حقيقة أهم جريمة إبادة جماعية ضد الإنسانية في القرن العشرين، حيث خلفت تلك التفجيرات النووية جرائم ضد

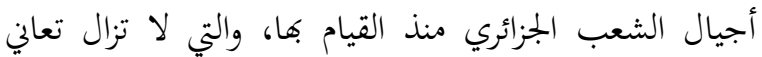

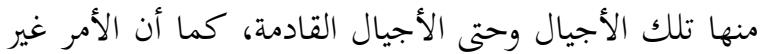
متوقف فقط على الإنسان، بل جرائم أثرت حتى في البيئة والنبات والحيوان والأرض أيضا.

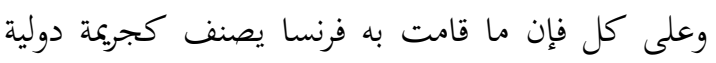
توفرت فيها جميع عناصر الجريمة؛ لذلك لا بد من من سعي السلطات الجزائرية الرسمية إلى المطالبة بالاعتراف الفرنسي لهري الرسمي بجرائم الإبادة النووية المنافية للأخلاق والإنسانية، وكذا برداب 


$$
\begin{aligned}
& \text { (40) نفس المرجع، ص. } 78 .
\end{aligned}
$$

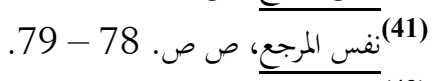

$$
\begin{aligned}
& \text { (42) نفس المرجع، ص. لمرجع، ص. } 79 .
\end{aligned}
$$

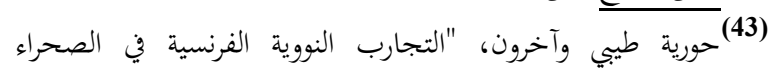

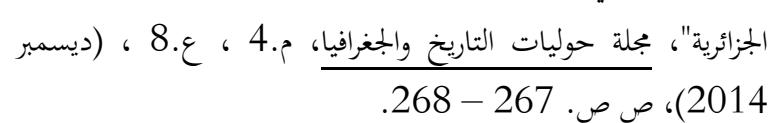
(44)

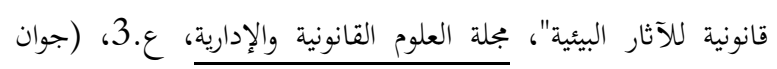

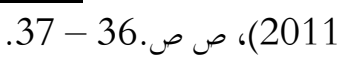

$$
\begin{aligned}
& \text { (45)نفس المرجع، ص. } 47 .
\end{aligned}
$$

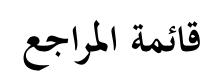$$
1
$$

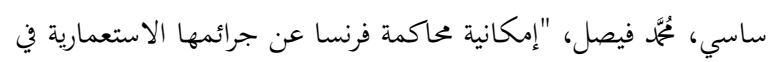

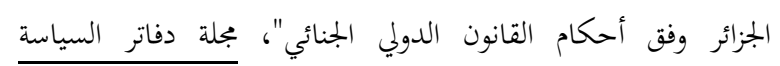

$$
\text { والقانون، ع. 8، (جانفي 2013) أحسام الفانون الرولي }
$$

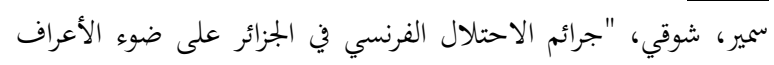

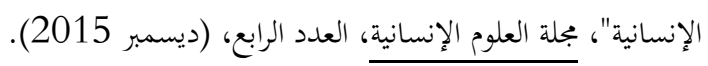

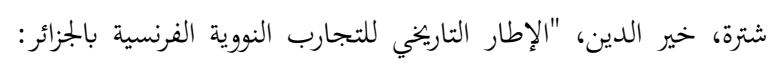

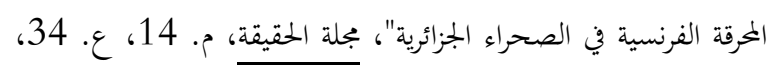
(سبتمبر 2015).

طيبي، حورية وآخرون، "التجارب النووية الفرنسية في الصحراء الجزائرية"،

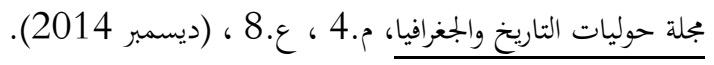

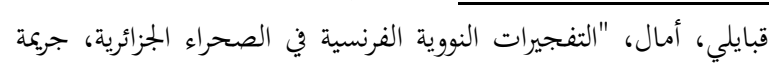

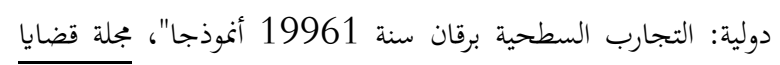
تاريخية، ع. 6، (2017). مريوة، صباح، "جرائم الحرب النووية في الصحراء الجزائرية: التجربة النووية

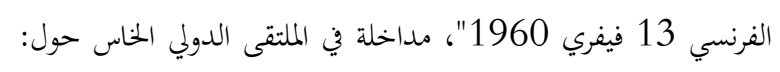

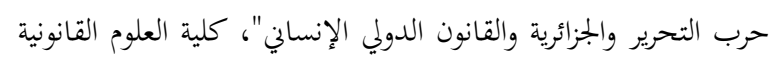

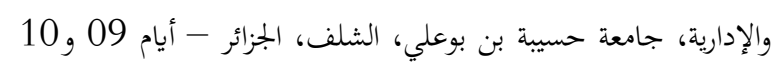

$$
\text { نوفمبر } 2010 .
$$

ميلوي، الزين، وبلويس، براهيم، "الثلوث البيئي: دراسة التفجيرات

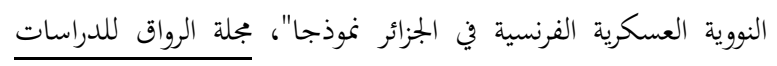

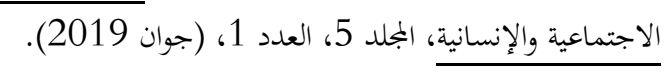

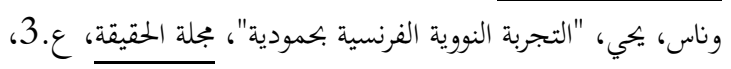
(ديسمبر 2003).
(12)""عسكري فرنسي سابق يقر بارتكاب بلاده جرائم نووية بالجزائر"،

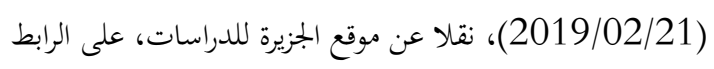

https://bit.ly/3ioNTsB

(13)"التجارب النووية الفرنسية بالجزائر .. المأساة المنسية"، مرجع سابق.

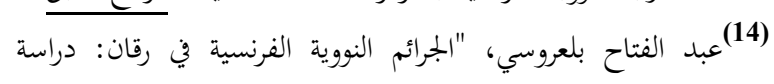

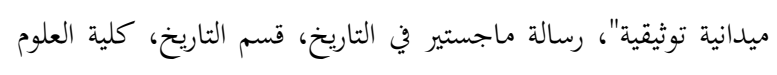

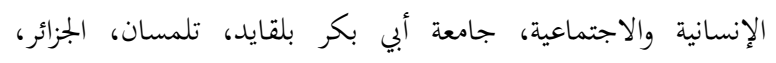

$$
\begin{aligned}
& \text { 2016/2015، ص. } 100 .
\end{aligned}
$$

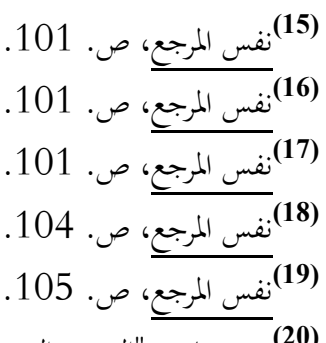

(20)

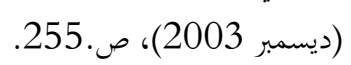

$$
\text { (21) خير الدين شترة، مرجع سابق، ص ص. } 255 \text { ص. } 69 \text { - } 70 .
$$

(22) شوقي سمير، مرجع سابق، ص. 19.

(23)

$$
\text { (24) نفس المرجع، ص. } 81 .
$$

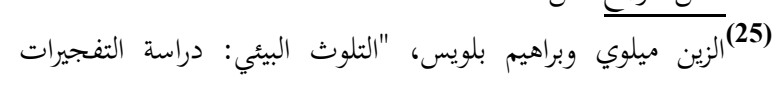

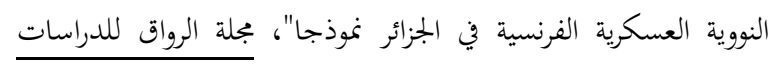

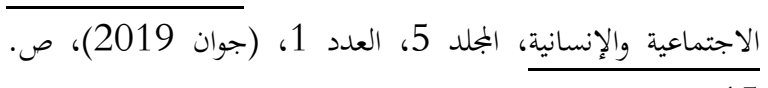

(26) عبد الفتاح بلعروسي، مرجع سابق، ص. 83.

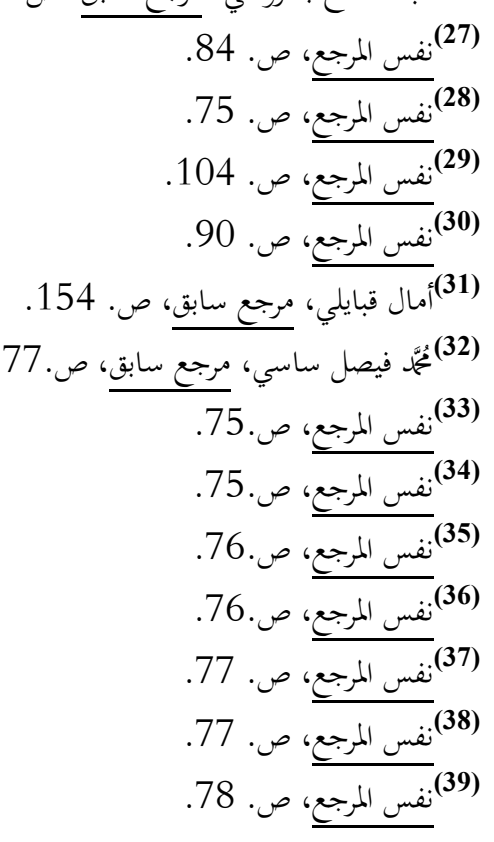




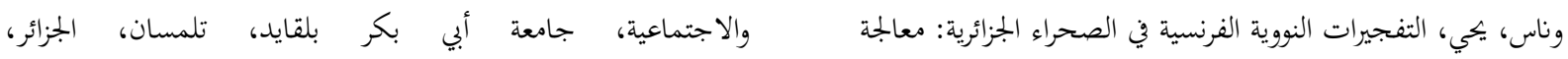

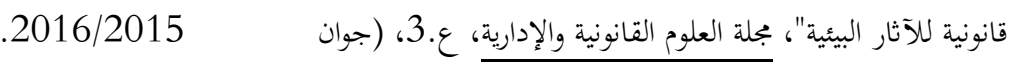

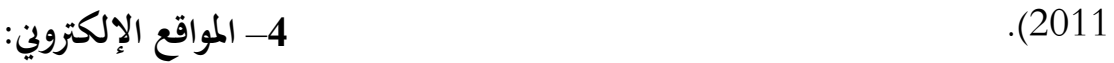

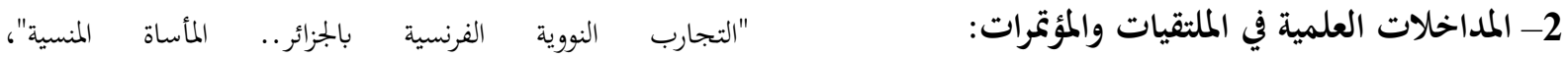

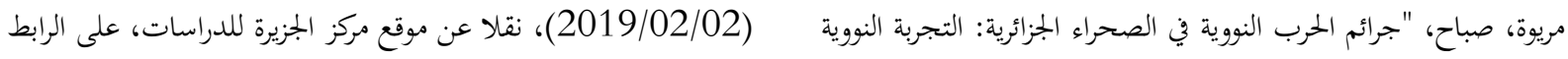

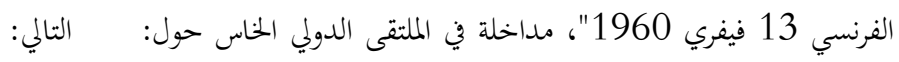

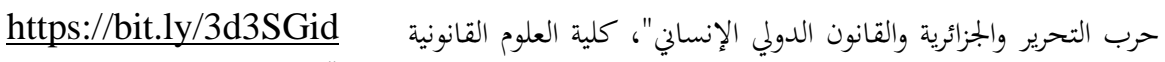

$$
\begin{aligned}
& \text { "التجارب النووية الفرنسية في الجزائر"، (2019/01/30)، نقلا عن } \\
& \text { الرابط التالي: https://bit.ly/3nfiGeT } \\
& \text { "عسكري فرنسي سابق يقر بارتكاب بلاده جرائم نووية بالجزائر"، }
\end{aligned}
$$

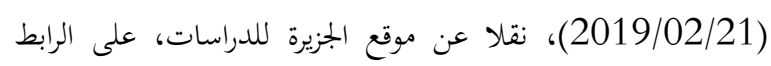

$$
\begin{aligned}
& \text { https://bit.ly/3ioNTsB }
\end{aligned}
$$

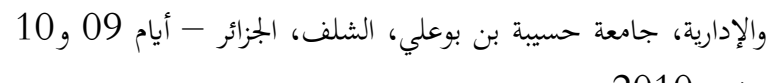

$$
\begin{aligned}
& \text { نوفمبر } 2010 . \\
& \text { 3- الرسائل والأطروحات الجامعية: }
\end{aligned}
$$

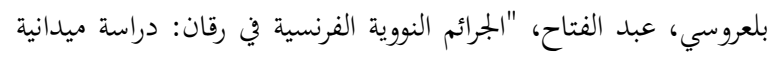

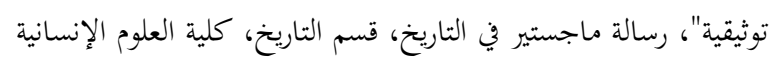

\title{
THE FRENCH NUCLEAR TESTS IN ALGERIA AS AN IMPORTANT MODEL OF GENOCIDE IN THE 20TH CENTURY
}

\author{
SHARIFA KALA'A \\ Dept. of International Studies, College of Political Sciences and International Relations. \\ Algeria University-Algeria.
}

\begin{abstract}
This study examines one of the most importance of studying genocide, by showing one of the most important historical examples in which there have been major violations against humanity, as the French bombings in Algeria are one of the most important examples of genocide in the 20th century, which had devastating effects at all levels. To clarify this crime against the Algerian people by the French colonialists, the reality and truth of the French nuclear genocide crimes in Algeria will be addressed, Arab and international reactions regarding the French nuclear genocide bombings in Algeria, the results of the genocide The French nuclear program in Algeria, and its devastating effects on the right of humanity, are acts that are considered international crimes because they fall within the contents of international agreements such as the Convention on the Prevention and Punishment of the Crime of Genocide in 1948 and the four Geneva Conventions, so French compensation should be demanded for the genocide crimes resulting from the nuclear explosions in Algeria .
\end{abstract}

KEY WORDS: Crimes - Genocide - Humanity - French nuclear explosions - in Algeria. 